\title{
Working virtually, exhausting in reality: Virtual cause of burnout in the age of a pandemic
}

\author{
W.T.G. Putra \\ Telkom University, Bandung, Indonesia
}

A.L. Hakim

Swasaba Research Initiative, Yogyakarta, Indonesia

T. Kartasudjana

Pasundan University, Bandung, Indonesia

\begin{abstract}
Until the middle 2020, the COVID-19 pandemic was still the central point of media conversation. A pandemic such as this one can greatly change human behavior and habis, notably increasing the human-internet interaction through the Work From Home (WFH) phenomena and its consequences. This study uses a digital anthropology approach as one of the strategies and entry points in understanding behavior in the digital world, and techniques for researching social interactions via digital technology. It will be presented in the form of autoethnography to describe and interpret cultural experiences, beliefs, practices, and texts. From the discussion, it shows that virtual and real spaces are connected, and the events between these two different spaces have an impact on each other. Burnout can be seen, not only as an outcome, but also as an indicator of cultural changes and shows the challenges video conferencing platform providers face in presenting experiences that visually and functionally accommodate its users.
\end{abstract}

Keywords: digital anthropology, work from home, digital culture, autoethnography, COVID-19 pandemic, burnout

\section{INTRODUCTION}

Until the middle of 2020 the COVID-19 pandemic was still the central point of media conversation. Pandemics can change human behavior and in other perspectives can be seen as a socio-cultural phenomena as infectious disease problems are biological and cultural, historical and contemporary, theoretical, and practical (Inborn \& Brown 2013). The handling and spreading of the virus related to the world view of a group of people about the world around them, which then forms a habit in the group. It includes social interactions, transforming the way they act and think.

In this century, regarding this customary negotiation, the pandemic then became central in the discussion of social science, especially anthropology. A 1909 work entitled "Les Rites de Passage" was written about how community groups respond to the presence of new people through habits and create some architecture for quarantine (van Gennep et al. 2013); related to disaster mitigation planning in swine flu (Atlani-Duault \& Kendall 2009), human behaviors and its spread (Inborn \& Brown 2013); Ebola and its handling related to community habits (Abramowitz 2017); and to discussions related to COVID-19 (Higgins et al. 2020). It also shows that massive pandemics and infectious diseases are part of the dynamics of human civilization and culture. How are the dynamics in Indonesia? This article will try to describe and record the cultural transformation that took place in Indonesia within the COVID-19 pandemic. The focus of this paper is on the Work From Home (WFH) phenomenon as jargon that emerged in Indonesia when the pandemic occurred, 
increasingly intense virtual interactions with the internet as a medium, and its impact on burnout in tangible forms as a consequence of WFH.

\subsection{Theoretical background}

The government's call for Large-Scale Social Restrictions (PSBB) forced some people in Indonesia to avoid direct physical contact. Due to the restriction of gatherings of humans in places with the potential to spread, some businesses allow workers to work from home, including school students. The transfer of work activities from real space (physical) to virtual space changes the habits of humans who interact in the arena. For example, an increase in internet traffic jumped by up to $20 \%$. This condition is a result of the use of virtual social interaction platforms, ranging from various social media that are commonly used (Facebook, Twitter, Instagram), to those whose interfaces are considered to be more "formal" (Zoom, Webex, Google Meet) as an alternative workspace. The use of the internet is increasingly felt to be a necessity; interaction through this new medium is considered a solution to the limitation of real interaction. The community negotiates itself in two different forms of space, both real and virtual.

Although it is often difficult to distinguish, the boundary between the two becomes vague; virtual phenomena are, of course, real in the sense of belonging to reality, and the words must be understood in the context (Nardi 2015). Despite having vague boundaries, the differences are seen quite sharply through the way they interact and behave in both spaces. Some scholars perceive how they interact in both spaces as cyberculture, a form of a culture focused on how humans create new forms of "technosociality," i.e., social modes of communication and being with others that are mediated by technology, as well as "biosociality," i.e., "A new order for the production of life, nature and body" (Escobar et al. 1994). There are differences in the presence of new forms of technology (in this case, the internet) that mediate human interaction in a new space/environment. Some of the views mentioned above emphasize the presence of new spaces (in the future referred to as virtual spaces) mediated by internet technology, forming specific ways of interacting (distinguishing them from real interactions), to forming ways of thinking of different cultures and having a connection with the real world and space.

The existence of interrelations and vague boundaries between real and virtual space shows that the two impact one another. For example, the presence of alternative spaces in the virtual world serves as a forum for opinion, including various forms of exchange in a broader definition. The effects of this exchange have an impact on real space, as well as virtual burnout, which impacts on real exhaustion.

The term burnout, used as a clinical term, was first proposed in 1974 by Herbert Freudenberger. Burnout refers to the emerging psychological syndrome as a prolonged response to chronic interpersonal stressors on the job (Maslach \& Leiter 2016). Burnout is vulnerable in people-oriented professions where work contacts take place both personally and emotionally, the needs of others take precedence over oneself, working hours are long, demands are high, and resources are limited (Maslach \& Leiter 2016). Likewise, with changes in the use of technology (mobile phones and computers) in the workplace, it can blur the boundaries between the world of work and home (Peeters et al. 2005). Rapid changes in habit patterns related to the perception of space and time between work and home are prone to lead to conflicting roles of related individuals. Like workhome conflicts that are defined as a form of inter-role conflict in which the role pressures from the work and family domains are mutually incompatible, such participation in one role makes it difficult to participate in the other (Greenhaus \& Beutell 1985).

\subsection{Objective}

The purpose of this study then is to: (1) document and show that burnout can occur in real space, as a result of interactions in virtual space; (2) reflect partially, how pandemics force affected communities to transform their habits as a part of a culture, especially a relationship between the working and non-working life in their daily lives; and (3) the existence of other factors-when virtual space is considered a real-world representation - makes this phenomenon so complicated. 


\section{RESEARCH METHODS}

This study uses a digital anthropology approach as one of the strategies and entry points in understanding behaviors in the digital world (Miller \& Horst 2012), and as a technique for researching social interaction via digital technology (Boelstorff et al. 2012). Analysis and qualitative data writing will be presented in autoethnography. Differing to other research methods, autoethnography, in its position as a research method, emphasizes the process of writing personal experiences ("auto") to describe and interpret ("graphy") cultural experiences, beliefs, practices, and texts ("ethno") (Ellis 2009; Adams et al., 2017) as a form of self-narrative that places the self within a social context. Here, autoethnographers are scholars that focus on using self as a medium intensely on their life circumstances as a way to understand larger social or cultural phenomena, and those who often uses personal narrative writing as a representational strategy that incorporates effects and emotions into their analysis (Butz \& Besio 2009). Autoethnography is a derivative of ethnographic research methods, which is one of the tools used in the field of anthropology, as well as being part of qualitative research methods. In autoethnography, researchers place themselves as insiders and outsiders in a research arena setting. As an insider, it means, researchers are active subjects in a cultural arena. In the context of this study, the researcher was directly and actively involved in a set of events, where he became a part of cultural events that took place during the pandemic. Researchers also create distance from these events. In this section, the researcher places himself as an outsider to write down perspectives and results to other subjects outside the researcher.

\subsection{Data collecting methods}

As previously written, in writing autoethnography and ethnographic writing in general, data is obtained, including through several ways, such as interviews, participant observation field notes, document and artifact analysis, and research diaries (Mayan 2001; Morse \& Richards 2002) as a cultural member of several community groups he studied. As part of that society, researchers try to obtain descriptions from several people through: (1) informal interviews to get their perspectives and perspectives on the phenomena they face, in addition to exploring personal memory to get a picture of collective memory when interrelations between data are found and trying to accommodate the views of others; (2) as a cultural member, researchers conduct participatory observation in several event settings in virtual spaces that are considered as "workplaces" as well as being part of them. In this study participatory observation is also used to ensure the involvement of researchers in field activities in everyday life settings and become well known to our informants (Boelstorff et al. 2012); (3) finally, examine a text through video recordings, photographs, and sounds (visual and verbal text), also the archives contained in journals. From the three methods, the researcher then writes his cultural experiences in several settings of events, classrooms, work, various webinars, and meetings outside the field of work (reunions, family gatherings, and limited discussion) in daily data known as fieldnotes. The field here refers to the arena/space of events that occur, in this case, a large part takes place in the virtual realm - some interviews are conducted face-to-face (real) - where humans do not often do face to face, as part of digital ethnography.

\section{DISCUSSION AND RESULTS}

\subsection{The blurred lines between the workplace and home, the real, and virtual}

On March 2, 2020 in Indonesia, the president announced the presence of patients 01 and 02 infected by this virus (Natalia \& Sofya 2020). A few months before, when this virus had only spread in Wuhan, workplaces were still operating as usual, with large numbers of meetings still being held, as other countries in Southeast Asia have begun to close their borders, limit social mobilization, and mitigate disasters related to how people interact. A bit of the story illustrates the initial conditions of this pandemic in Indonesia. 
The workplace, as commonly found in Indonesia, is a space where people gather. As the cluster of the spread of this virus before, public places increased awareness, protocols, and new ways of working were implemented. Some offices have a shift system for their employees, to ensure the quota of people who interact within a space is within safe limits. The rest can still work from home, commonly known as Work From Home (WFH), by utilizing a video conference platform.

The habit of working at home is changing human habits in addressing their space, and various adjustments were made. It starts from setting up the room at home as a workplace, so that makes it feasible when displayed on the screen, likewise with interaction patterns that must be adapted to digital "novelty" in this pandemic era. The phenomenon in this WFH condition is that the boundary between the home and office is blurred, so is the boundary between virtual and real spaces, where the need for human interaction through the internet is becoming more intense.

\subsection{A real presence in virtual space}

A few days after the PSBB was carried out, almost simultaneously, various agencies, both public and private, moved their offices into a virtual space. In principle, this virtual space mimics face-to-face interaction in the meeting room in daily practice, where there are people gathered in the same room. The way they communicate can be adjusted by users, using sound, video, both, and deactivating one or all of them. Users can also display photos or names, whether original or disguised as an identity marker that they are present in the room. This phenomenon is known as an avatar, a representation of humans in a virtual world (Boelstorff et al. 2012). The processes of "imagining yourself" in an unknown space (Malinowski 2014), and the embodiment of characters in a virtual world adapted from the Sanskrit language, meaning the embodiment of "God on Earth" (Kerschbaumer 2016).

At the beginning of the use of digital platforms as an alternative to this real space, users are still trying to get used to it. Some of them forget to turn off their microphones when other people are talking, or family members in the background can be seen. The sounds that are considered as interference are often heard. The rest seemed accustomed to turning off the microphone, while their faces seemed to move on the screen, indicating their real presence in the virtual space. Only a few do not turn on the camera and microphone, but there are names as an indicator of their presence. These events color everyday interactions that are slowly trying to be normalized and accustomed, which is how social interaction should be during a pandemic.

The following days, the use of video conferencing platforms became more frequent and intense. Some subjects in this study tell that, often, have to attend this virtual meeting at the same time and with the same priority scale. Usually, they will use more than one gadget to fulfill its role in different spaces. Not infrequently, the meeting lasts into the evening, until finally impacting on the physical fatigue felt by some subjects in real, although this interaction is done virtually. Once at a meeting, a virtual meeting member said, "If someone asks to have a meeting, (using a video conference platform) just serve. What is the difficulty in just turning on the computer and sitting to attend the meeting?"

In practice, working virtually through video conferencing earlier has more or less the same impact felt by some people. Seen in some of the 'mandatory' tasks given by the institutions where they are active, some of them began to outsmart their presence in the virtual space. Seen in the virtual space, some of them began to put photos of their faces in impressive poses, through body language, as if they were in the room. Others use the gif (Graphical Interchange Format) feature to make their presence more visible, with repetitive patterned movements. Similar to the avatar phenomenon described earlier, presence in the virtual realm is only a representation of the presence itself, which manifests in the form of sound, static, and moving images.

\subsection{Intertwined power relations in real and virtual space}

The presence and obligations in the virtual space do not necessarily eliminate the role in the real space, in this case, a house that doubles as a workspace, where individuals also have specific and diverse obligations and roles. In some instances, the writer is faced with the conditions of having 
to negotiate with other members of the meeting, whether the writer or they are asking permission not to attend the meeting because there are roles/obligations in the real space that must be fulfilled, usually related to family members. At this point, it indicates the presence of virtual space in real life, leading the subject to more complex power relations at the same time. In effect, this power relation is then negotiated, hoping for the discovery of new points of balance in a culture that changes rapidly and in a hurry during this pandemic.

\section{CONCLUSION}

"I don't know why I feel so tired. I only sit and attend several online meetings a day, both those required by the institution where I work, as well as meetings related to my hobbies and interests. Often, my days end with exhaustion, and even quite often, I find myself easily provoked and angry to yell at other family members at home, hitting the side of the table near me at work, and wanting to sleep all-day, whereas when I was at the office, those are conditions I have never experienced. It feels strange."

The melting of the boundaries between the real and the virtual world through internet interactions, which is getting higher in intensity, has a consequence that humans have to renegotiate their position in the cultural transformation that occurs. The virtual and the real space are interconnected, and the events between these two different spaces impact each other. The Internet, as a medium that forms virtual space, still uses the time and space constraints that apply in their interactions in real space. Burnout, in the end, is not only an outcome, excess, or residue that arises from the presence of the trigger factors previously described. Burnout, in this article, can be seen as an indication of a rapidly transforming culture, requiring humans to impose new standards on themselves - "normal vs new normal" - as well as a sign that humans are faced with an existential crisis that they are still negotiating with. This condition also shows the challenges video conferencing platform providers face in presenting experiences that visually and functionally accommodate its users. At the same time, reconsidering digital technology as a tool, does it make their job easier? Or, do we, as humans, do the job from technology in today's digital era?

\section{REFERENCES}

Abramowitz, S. 2017. Epidemics (Especially Ebola), Annual Review of Anthropology. doi: 10.1146/annurevanthro-102116-041616.

Adams, T. E., Ellis, C., and Holman Jones, S. 2017. A brief history of autoethnography, The International Encyclopedia of Communication Research Methods, (August). doi: 10.1002/9781118901731.iecrm0011.

Atlani-Duault, L. and Kendall, C. 2009. Influenza, anthropology, and global uncertainties, Medical Anthropology: Cross Cultural Studies in Health and Illness. doi: 10.1080/01459740903070519.

Boelstorff, T. et al. 2012. Ethnography and Virtual Worlds: a handbook of Method. Princeton, Oxford: Princeton University Press.

Butz, D. and Besio, K. 2009. Autoethnography, Geography Compass, 3(5):1660-1674. doi: 10.1111/j.17498198.2009.00279.x.

Ellis, C. 2009. Autoethnography as Method (review), Biography, 32(2):360-363. doi: 10.1353/bio.0.0097.

Escobar, A. et al. 1994. Welcome to Cyberia: Notes on the Anthropology of Cyberculture [and Comments and Reply], Current Anthropology. doi: 10.1086/204266.

van Gennep, A., Vizedom, M. B., and Caffee, G. L. 2013. The rites of passage, The Rites of Passage. doi: $10.4324 / 9781315017594$.

Greenhaus, J. H. and Beutell, N. J. 1985. Sources of Conflict Between Work and Family Roles, Academy of Management Review. doi: 10.5465/amr.1985.4277352.

Higgins, R., Martin, E., and Vesperi, M. D. 2020. An Anthropology of the COVID-19 Pandemic, Anthropology Now. Routledge, 12(1):2-6. doi: 10.1080/19428200.2020.1760627.

Inborn, M. C. and Brown, P. J. 2013. The anthropology of infectious disease, in The Anthropology of Infectious Disease: International Health Perspectives. doi: 10.4324/9781315078366-10. 
Kerschbaumer, L.-M. M. 2016. Anthropology of virtual worlds: history, current debates and future possibilities, Grafo Working Papers, 5:95. doi: 10.5565/rev/grafowp.21.

Malinowski, B. 2014. Argonauts of the western pacific: An account of native enterprise and adventure in the archipelagoes of Melanesian New Guinea, Argonauts of the Western Pacific: An Account of Native Enterprise and Adventure in the Archipelagoes of Melanesian New Guinea. doi: 10.1017/9781315772158.

Maslach, C. and Leiter, M. P. 2016. Understanding the burnout experience: Recent research and its implications for psychiatry, World Psychiatry. doi: 10.1002/wps.20311.

Miller, D. and Horst, H. 2012. Digital Anthropology, Berg. Edited by H. A. D. Miller and H. Horst. London, New York: Berg.

Nardi, B. 2015. Virtuality, Annual Review of Anthropology, 44(1):15-31. doi: 10.1146/annurev-anthro-102214014226.

Natalia, D. L. (Antara) and Sofya, H. (Antara). 2020. Presiden umumkan kasus infeksi corona pertama di Indonesia. antaranews.com. Available at: https://www.antaranews.com/berita/1329594/presidenumumkan-kasus-infeksi-corona-pertama-di-indonesia.

Peeters, M. C. W. et al. 2005. Balancing work and home: How job and home demands are related to burnout, International Journal of Stress Management. doi: 10.1037/1072-5245.12.1.43. 